\title{
Das "profundezas do espaço": considerações sobre o jogo de futebol de um ponto de vista da teoria espacial e corporal
}

From the "depths of space": considerations about the soccer game from a space and body theory point of view

Desde las "profundidades del espacio": consideraciones sobre el juego de fútbol desde un punto de vista de la teoría espacial y corporal

Elenor Kunz, Reiner Hildebrandt-Stramann" ${ }^{\mathrm{II}}$, Aguinaldo Surdi ${ }^{\mathrm{III}}$

\begin{abstract}
Resumo
A fenomenologia, enquanto filosofia, esclarece muitos e grandes temas relacionados à eventos e condições humanas e que muito dizem respeito ao campo da Educação Física e dos Esportes. No presente artigo, os autores fazem uma pequena incursão teórica nessa filosofia sobre a temática do Espaço e apresentam esse olhar fenomenológico para o campo de jogo, no caso do futebol, e a formação profissional em Educação Física. Com isso, tem-se, como consequência didática, acima de tudo, que os jogos ensinados e aprendidos, a partir dessa compreensão, seguem o princípio do "aprender brincando", e não "aprender se adaptando às destrezas técnicas". Didaticamente falando, podemos dizer, então, que o ensino dos jogos esportivos segue o princípio dos "conceitos abertos do ensino de jogos".
\end{abstract}

Palavras-chave: Fenomenologia, Futebol, Educação Física

\begin{abstract}
Phenomenology, as a philosophy, clarifies many and great themes related to human events and conditions, which are related to the field of Physical Education and Sports. In this article, the authors make a small theoretical incursion into this philosophy on the theme of Space and present this phenomenological look at the playing field, in the case of soccer, and professional training in Physical Education. Thereby, the didactic consequence, above all, is that the games taught and learned, based on this understanding, follow the principle of "learning by playing", and not "learning by adapting to technical skills". Thus, didactically speaking, we can say that the teaching of sports games follows the principle of "open concepts of game teaching".
\end{abstract}

Keywords: Phenomenology, Soccer, Physical Education

${ }^{\text {I } U n i v e r s i d a d e ~ F e d e r a l ~ d e ~ S a n t a ~ C a t a r i n a ~-~ U F S C ~-~ E n d e r e c ̧ o: ~ R . ~ E n g . ~ A g r o n o ̂ m i c o ~ A n d r e i ~ C r i s t i a n ~ F e r r e i r a, ~ s / n ~-~ T r i n d a d e, ~ F l o r i a n o ́ p o l i s ~-~ S C, ~} 88040-900$ - eMail: elenkunz@terra.com.br

${ }^{\text {II }}$ Universidade Técnica de Braunschweig (Institut für Sportwissenschaft und Bewegungspädagogik - Technische Universität Braunschweig) - e-mail:

R.Hildebrandt-Stramann@tu-bs.de

II Universidade Federal do Rio Grande do Norte - UFRN - e-mail: aguinaldosurdi@yahoo.com.br 


\section{Resumen}

La Fenomenología, como filosofía, aclara muchos y grandes temas relacionados con los eventos y condiciones humanas, que se relacionan con el campo de la Educación Física y el Deporte. En este artículo, los autores hacen una pequeña incursión teórica en esta filosofía sobre la temática del Espacio y presentan esta mirada fenomenológica al campo de juego, en el caso del fútbol, y la formación profesional en Educación Física. Con eso, tiene como consecuencia didáctica, sobre todo, que los juegos enseñados y aprendidos, a partir de esta comprensión, siguen el principio de "aprender jugando", y no de "aprender adaptándose a las habilidades técnicas". Didácticamente hablando, podemos decir, entonces, que la enseñanza de juegos deportivos sigue el principio de "conceptos abiertos de enseñanza de juegos".

Palabras clave: Fenomenología, Fútbol, Educación Física

\section{Introdução}

No atual discurso pedagógico, sobre a legitimação da Educação Física como uma disciplina necessária no contexto da educação escolar de crianças e adolescentes, constantemente aparece uma questão importante sobre a qualidade pedagógica na formação de professores de Educação Física (HILDEBRANDT-STRAMANN, HATJE, 2020).

Quando a Educação Física na escola é considerada uma disciplina oficialmente autorizada, como as demais disciplinas, tais como português, matemática, ciências, história, arte, entre outras, surge, imediatamente, uma questão relacionada à sua especificidade, ou seja, o que caracteriza, especificamente, um "se-movimentar" (KUNZ, 1991) de crianças e jovens para uma aula de Educação Física no contexto da Escola?

Para a especificidade das demais disciplinas, anteriormente mencionadas, é possível dizer que elas promovem uma forma específica no complexo relacionamento de homem-mundo, ou seja, nessas disciplinas - tanto nas ciências humanas, como nas ciências naturais - a forma mais especial e direta desse relacionamento se dá através da linguagem (isto é, falando) e da literatura (isto é, lendo). Falando e lendo o aluno descobre o mundo da linguagem, assim como da literatura, dos símbolos e das fórmulas. Já nas disciplinas como "Arte", "Música" e, também, na "Educação Física", o modo específico de relacionamento homem-mundo se apresenta pelas configurações estético-expressivas de suas manifestações, ou seja, pelo ritmo, no caso das melodias que acompanham os movimentos corporais, etc. Na disciplina "Educação Física", esse relacionamento estético-expressivo se manifesta, prioritariamente, num "se-movimentar" corporal. Corpo e movimento se tornam, assim, agentes de um relacionamento homem-mundo bem específico e com uma possibilidade muito especial de aprender e conhecer. 
Nessas situações de experiências do e no mundo, realizadas por um "se-movimentar" de crianças e jovens, ocorrem experiências tão específicas que não podem ser apreendidas somente pelo estudo/ aprendizagem, através da linguagem verbal ou pela literatura. Tais experiências relacionam-se com ritmo, equilíbrio, prática social, mas também com tempo e espaço. O aluno obtém conhecimento específico do mundo quando é habilitado, no ensino escolar, a refletir sobre essas experiências corporais e de movimento. O mesmo vale para um estudo acadêmico na formação profissional em Educação Física, apesar de que, nesses âmbitos, o nível das experiências de aprendizagem deve ser significativamente mais elevado.

Isso significa que o estudante, em seu estudo universitário, deve aprender, entre outros assuntos, por exemplo, a como encenar, didaticamente, temáticas de movimento em uma aula de Educação Física escolar, para que consigam, no futuro, possibilitar a seus alunos na escola um acesso esteticamente expressivo ao mundo.

Nesse contexto, o que significa estudar movimentos? A seguir, gostaríamos de discutir essa questão, usando o exemplo da prática do futebol, ou seja, como "estudar o futebol". Vamos nos limitar aos aspectos do espaço e à percepção do espaço. Deve ficar claro que "estudar futebol", no contexto dos estudos universitários, é mais do que praticar as técnicas e táticas de jogar futebol. O "estudo do jogo de futebol" significa - usando o exemplo de espaço - encenar um encontro esteticamente expressivo com o espaço de jogo e refletir sobre as experiências feitas nessa encenação, a partir de uma perspectiva da teoria da percepção e da teoria do espaço.

Estruturamos nossas considerações da seguinte maneira: em um primeiro passo, explicaremos, da perspectiva da experiência própria de um dos autores, o que pode significar, do ponto de vista de um jogador de futebol, o agir "no espaço". Em um segundo passo, vamos teoricamente transcender essa perspectiva e abordar o tema do espaço de um ponto de vista fenomenológico, ou seja, fenomenologia filosófica.

Portanto, o estudo dessa temática, com esses dois primeiros passos, tem a ver, sobretudo, com alcançar uma abrangência bem maior, ou seja, busca auxiliar a tarefa real de um professor de Educação Física, envolvido no projeto de aprendizagem de diferentes contextos de um "se-movimentar" escolar, que conduza à promoção do autodesenvolvimento de crianças e adolescentes. Concretamente, desenvolveremos essa reflexão no terceiro passo, logo mais. Então, iniciaremos com a seguinte questão: que orientações didático-pedagógicas, com a temática em desenvolvimento, um estudante de graduação pode ganhar, quando vier apoiada em uma reflexão com base na teoria da percepção e da teoria de espaço? 


\subsection{O espaço sob uma perspectiva - implícita pessoal e externa aleatória}

De uma perspectiva externa aleatória, ou seja, da perspectiva de um espectador de arquibancada, o espaço é visto como um fenômeno, podemos dizer, quadrangular. A perspectiva é a de um observador objetivamente orientado, ou seja, com foco em algo e, dessa forma, vê o movimento em um sistema de referência espacial que existe independentemente do próprio observador.

Porém, no momento em que abandonarmos a arquibancada e entrarmos, efetivamente, para dentro de um campo esportivo, vivenciaremos esse campo de forma bem diferente do que da arquibancada. Se formos ainda mais longe, e nos colocarmos, de fato, na posição de um ator do movimento nesse campo, então surgirá, ainda, outra situação da Dimensão do Espaço e do movimento. Essa é, então, uma dimensão muito especial, que podemos chamar de Vivência Espacial, em que o ator, pelo seu "semovimentar", configura uma relação muito especial com o espaço em que se encontra.

Assim, se observarmos jogadores de futebol, no seu espaço de se movimentar de forma específica, poderemos verificar que esses jogadores parecem se fundir em unidades simbióticas.

Praticamente, da mesma forma, podemos dizer que é maravilhoso quando um jogador de futebol, em um rápido giro sobre si mesmo, executa um lançamento para a profundidade do espaço do campo de jogo e a bola encontra seu objetivo. Em ambos os casos, podemos dizer, metaforicamente, que atletas altamente treinados, em seus respectivos campos de ação, conseguem agir de forma "cega". Podemos considerar essa qualidade na relação espaço-corporal como resultado de uma exploração ativa e uma abertura de espaço pelo seu movimento próprio, cujo movimento próprio, neste caso, é constitutivo, porque esses espaços específicos para o "se-movimentar", com suas possibilidades de realização de experiências, somente são possíveis com, e através, de movimentos próprios.

Espaço e movimento e a constituição do espaço de movimentos são baseados na tese de Buytendijk (1956), em uma conexão funcional entre espaço e sujeito. No contexto dessa tese, a questão a ser discutida na sequencia é como os espaços, na realização de atividades esportivas, são estruturados para os praticantes/ atores. Discutiremos essa tese, de uma perspectiva biográfica, de um dos participantes deste artigo, na qualidade de ex-jogador de futebol.

\section{Vivência espacial do jogador de futebol}


Agora vamos tratar de um caso muito especial: como um jogador de futebol vivencia, na realidade do campo, esse espaço que acima mencionado?

Aqui, tratamos de analisar as experiências vividas por um dos autores do artigo, além de sua atuação como ex-jogador de futebol no campo de jogo. Assim, formamos quatro pares de categorias que caracterizam essa vivência e experiência:

1. Abertura - fechamento;

2. Longe - perto - atingível e inatingível;

3. Com sentido - sem sentido;

4. Liberdade - controle.

\subsubsection{Primeiro par de categorias: abertura - fechamento}

Para um jogador de futebol, em um campo de jogo, o fenômeno do espaço, em uma visão em constante deslocamento, consiste em uma espécie de abertura e de fechamento. Isso vale tanto para o seu próprio movimento, nos deslocamentos que realiza quando joga, quanto para o objeto do jogo, a bola, que precisa ser deslocada também de uma região do campo para outra. O jogador procura sempre um espaço aberto, um espaço mais "livre", por assim dizer. Ele se movimenta nesse espaço mais livre para, por exemplo, estar sempre em melhor situação de receber a bola. Com a posse de bola, então, ele procura por um espaço vazio, entre a "parede" de jogadores adversários, para dar um passe certeiro aos seus companheiros de jogo. "Parede" e "espaço vazio" ou "lacuna"” são metáforas que representam o par de categorias "abertura (lacuna) e fechamento (parede)".

No entanto, isso representa aqui uma padronização em um fluxo de acontecimentos. A abertura e o fechamento, no desenrolar de um jogo, não ocorrem como algo dado, mas como algo a ser antecipado. Um jogador experiente, e que sabe jogar muito bem, chuta a bola somente para o espaço do campo de jogo onde algo de positivo realmente pode acontecer para o seu time. Abertura e fechamento representam, para o bom jogador, certo fluxo padrão: quem tem consciência disso, sabe que não se encontra, verdadeiramente, no momento do "agora", e sim, no momento do "mas então", porque percebe que a abertura e o fechamento do espaço de jogo ocorrem por meio de suas próprias ações no jogo. Então, em consequência disso, ele executa suas ações de jogo. 
O iniciante, por outro lado, percebe, na maioria das vezes, seus adversários como uma parede intransponível. Ele tem dificuldade em ver lacunas no espaço de jogo, de modo que, como sua visão está totalmente ocupada pelos adversários, a bola é passada rapidamente para o companheiro de jogo mais próximo. Esse iniciante fica limitado, ao que acima falamos, ao momento do "agora". Ao contrário do jogador experiente, que consegue constantemente relacionar-se com um modo futuro, do "logo então", e que se manifesta como uma intuição, uma inspiração, em situações onde realiza um passe em profundidade no espaço de jogo, para um espaço aberto na sua percepção, quando vê/ sente (intuição) de que há lacunas ou espaços livres para esse passe.

\subsubsection{Segundo par de categorias: "longe e perto", alcançável e inalcançável}

Entendemos a categoria "Longe e Perto" no sentido de um "alcançável” ou "inalcançável”. Isto é, jogando futebol, sempre se medem distâncias na configuração do espaço/ campo de jogo. Isso ocorre com base nas habilidades técnicas, bem como na própria capacidade de jogar. Estamos continuamente avaliando se nosso companheiro de jogo, ou a goleira para onde a bola deve ser direcionada, estão perto ou longe de nós, ou seja, estamos sempre avaliando os espaços pelas categorias de "longe" ou "perto".

As conclusões que tiramos dessa avaliação dependem muito do tempo de treinamento e, com isso, das habilidades técnicas adquiridas, tanto em relação ao trato com a bola, quanto com o relacionamento técnico-tático com meus companheiros de jogo. Fica evidente, assim, que o par de categoria "Longe e Perto" vai adquirindo significados diferentes para cada jogador, de acordo com suas condições físicas e suas habilidades técnicas.

\subsubsection{Terceiro par de categorias: Com Sentido ou Sem Sentido}

Basicamente, podemos dizer que o campo de jogo, melhor dizendo, o espaço de jogo, é estruturado de acordo com as ações do jogo. Cada jogador concebe a estrutura do campo de jogo de acordo com sua habilidade e velocidade que julga possuir. No sentido do Movimento-próprio, podemos dizer que o Espaço é propriamente o campo de jogo, no qual estamos com os companheiros jogando e, evidentemente, incluindo os adversários naquele instante. O jogo em si está relacionado ao tempo de jogo, bem como ao tempo de ocupação de cada espaço no campo de jogo por todos os jogadores. Um exemplo disso é um passe de bola. Antes do passe ser realizado, o espaço a que nos referimos apresenta- 
se ao jogador, na verdade, como um espaço de oportunidade. Porque, se não fosse assim, o passe não seria realizado. Portanto, esse passe realizado permite que, neste momento do "agora", o espaço do campo de jogo adquira um novo significado. Isto é, originalmente, anterior à realização do passe, o espaço obviamente já possuía um significado.

Para ser mais preciso, a ação do jogo - do ponto de vista euclidiano - dá sentido a certos quadrantes do campo de jogo. O passe, nesse quadrante, transforma o espaço de oportunidade em êxito do lançamento ou, por outro lado, em zona de perigo, uma vez que a equipe adversária pode tomar a posse dessa bola em lugar dos nossos companheiros de jogo. Essa ação do passe se transforma em algo de grande significado, porque, através dele, uma situação mais significativa do jogo pode ser construída. Do ponto de vista do jogador, essa retransformação da visão de espaço se constitui em um "Lance de pura Arte". Portanto, a capacidade de antecipar significados espaciais no campo de jogo, e de utilizá-la para jogar adequadamente, configura uma capacidade artística e uma expressão de vanguarda.

Isso nos permite dizer, nesse caso, que o Lugar (campo de jogo) pode ser modificado pela Ação, de tal forma que um Lance de Passe no futebol pode também ser interpretado como arte da Ressignificação da Ação. Nisso, é possível interpretar, também, um Momento do Estético, porque a influência funcional que o Espaço oferece transforma-se em uma vivência estética, o que, na linguagem do futebol, significa, aquele "passe magistral"

\subsubsection{Quarto Par de categoria: espaço de liberdade e espaço de controle}

No desenvolvimento de um jogo, os jogadores procuram estruturar o espaço do campo de forma a aumentar, cada vez mais, os espaços de liberdade para jogar e diminuir, na mesma proporção, os espaços de controle, ou seja, os espaços controlados pelo adversário. Esses dois tipos de ações intencionadas pelos jogadores se encontram, ao mesmo tempo, no fluir da partida. Por esse motivo, uma tarefa importante para o jogador, nesse caso, é impedir as restrições de ações pela ampliação dos espaços de sua movimentação. Em outras palavras, podemos dizer que o jogador está, constantemente, na busca de uma "rota de fuga", já que ele precisa buscar espaços de menor congestionamento de jogadores adversários. A intenção sempre é a de evitar o confronto direto com o adversário, especialmente os defensores.

Nesse sentido, as ações do jogo, bem como as jogadas com os companheiros de jogo, são sempre uma busca de mais liberdade para ações de jogadas, em terreno ou espaço controlado pelos adversários. Isso significa, portanto, uma dialética das ações de jogo com a única intenção de manter o controle do 
espaço de jogo. Controle significa restringir a influência do oponente. Quem controla o espaço de jogo, no caso do futebol, aqui tratado, tem também o domínio ou o poder sobre o espaço total em que o jogo se desenvolve. A esse respeito, o espaço de jogo também pode ser visto como um espaço de dominação ou de domínio. Na perspectiva da percepção dos jogadores, trata-se, na verdade, de uma busca de predomínio sobre o espaço de jogo pela ocupação do "terreno", cercando zonas do campo onde o adversário possa conquistar também algum espaço próprio para suas jogadas. O adversário naturalmente procura uma atitude complementar, ao tentar se contrapor a qualquer tipo de ocupação de espaços e de resistir à dominação do campo de jogo.

No entanto, para um jogador, a experiência de estar em um espaço de jogo não é apenas uma experiência com esse espaço, é também, e sobretudo, uma experiência emocional. A experiência com o espaço no campo de jogo ocorre, para um jogador, na base de vivências do campo, dividido em regiões com mais ou menos ocupação de adversário para administrar, com melhor êxito, as suas jogadas.

É certo que, onde os espaços do campo estão sob um controle maior dos adversários ou nos pontos mais perigosos, tanto para o ataque como para a defesa, o jogador encontra-se em um estado emocional mais oprimido. Se for um atacante, ele encontra-se em uma região do campo mais controlada pelo adversário e, por isso, suas ações de jogo ficam cada vez mais ameaçadas, o que leva a, cada vez mais, modificar essa situação.

Desse modo, para modificar essa situação opressora de jogo, o jogador procura encontrar espaço de baixa densidade de controle do território, e isso também se refere ao objeto do jogo, a bola, que, pelo passe, o jogador também procura encontrar espaços mais livres para contribuir com melhores jogadas de seu time.

\subsubsection{Resumo}

Entendendo a experiência espacial como um fenômeno do agir ou de uma ação, então "experiência espacial", no caso de um jogador, como aqui analisado, significa:

- Ter liberdade e autorização para reinterpretações;

- O jogador, no caso, encontra-se no centro de um horizonte de amplas e surpreendentes possibilidades;

- Ele se coloca em zonas menos controladas e de ações menos intensas para, assim, poder desenvolver melhor suas ações de jogo; 
- A constante busca por espaços mais livres está diretamente ligada à intencionalidade do jogador para alcançar certa supremacia do espaço de jogo. Surgindo das profundezas sombrias do espaço, ele alcança, pelas ações de suas jogadas, rapidamente, a clareza espacial, ou seja, uma visão de jogo ampla sobre a totalidade dos espaços existentes.

\section{Sobre a compreensão do espaço na Fenomenologia}

Assim como em relação ao tempo, podemos distinguir entre o tempo abstrato e matemático, que pode ser medido com relógios ou cronômetros, e o tempo realmente vivenciado por pessoas vivas; do mesmo modo, também é possível estabelecer diferenças entre o conceito de espaço abstrato dos matemáticos e físicos e o espaço humano concretamente experimentado. Quando falamos de espaço, na vida quotidiana, sem refletir sobre ele, geralmente pensamos em um espaço matemático, o espaço que pode ser medido em suas três dimensões por metros, centímetros e milímetros. É a compreensão de espaço que aprendemos na escola e que, constantemente, usamos para estabelecer relações espaciais mensuráveis na vida prática (por exemplo, quando estivermos pensando em como podemos organizar um novo espaço para nossos móveis quando nos mudamos para um novo apartamento). Por outro lado, raramente nos tornamos conscientes de que esse é apenas um certo aspecto do espaço, e que o espaço concreto, vivenciado diretamente na vida, não coincide com esse espaço matemático abstrato.

Queremos ilustrar brevemente esse fato usando o exemplo do espaço nos esportes. Inicialmente, tomamos a perspectiva de um espectador na arquibancada. O espectador, na arquibancada, percebe o espaço de jogo na forma matemática. Ele vê um espaço de jogo retangular, onde jogadores se movimentam para várias direções, assim como a bola com que jogam. Desse lugar, ele consegue obter uma visão geral de todo o evento, ele adota a "perspectiva de um capitão do mar (no sentido militar mesmo)", por assim dizer. Para o ambiente esportivo, o significado de um campo de jogo na forma retangular, e suas dimensões padronizadas, é feito para garantir as condições estruturais e para se conseguir as comparações objetivas, do princípio básico do esporte (KUNZ, 1991) e, com isso, os resultados justos. Portanto, as regras espaciais pertencem às regras constitutivas dos esportes. $\mathrm{O}$ que o espectador da arquibancada vê é um domínio da geometria, caracterizada pela competição, e suas regras de comparações objetivas para o rendimento. Com isso, a perspectiva de espaço, de um espectador da arquibancada, é frontalmente diferente sobre a visão do mesmo espaço do que para um jogador em ação no campo de jogo. 
A perspectiva de espaço de um jogador está mais relacionada ao espaço vivido, ao espaço da experimentação humana. O espaço vivido constitui-se a partir das ações desenvolvidas pelos envolvidos num campo de jogo. É possível verificar isso, de forma espetacular, no futebol de crianças, as chamadas “peladas infantis". Nessa situação, podemos perceber que as crianças determinam algumas marcações no espaço de jogo, que não são fixas, pois elas podem ser modificadas a qualquer momento, de acordo com as intenções de jogo dos envolvidos. Por exemplo, as dimensões do campo ou as goleiras podem mudar de acordo com o número de participantes do jogo e, até mesmo, considerando as habilidades técnicas dos jogadores.

\subsection{As dimensões corporais do espaço}

O espaço concreto e vivido é um tema muito presente na perspectiva fenomenológica. "Este espaço é para o Si próprio”, escreve Dürckheim (1932, p. 389; apud BOLLNOW, 2008, p. 20). Com isso, ele quer dizer que o espaço não é um objeto separado do sujeito, mas um meio ligado ao sujeito e pode ser experimentado corporalmente. Logo, vem a pergunta: Quais são as dimensões corporais do espaço?

A base das dimensões corporais humanas são as seguintes:

- a dimensão vertical, ou seja, a dimensão corporal do "em cima - em baixo";

- a dimensão corporal esquerda - direita;

- a dimensão corporal frente - atrás.

\subsubsection{A dimensão vertical corporal}

O significado básico para o conceito da verticalidade corporal é baseado na interação de vários fatores relacionados à postura corporal ereta. De um lado, existe a simetria do eixo vertical do corpo e, portanto, a fronteira entre o espaço da esquerda e o espaço da direita. Por outro lado, a postura corporal ereta é controlada por um órgão de equilíbrio que sinaliza desvios da verticalidade corporal, como estados de desequilíbrio, e esse órgão de equilíbrio é, ele próprio, mecanicamente calibrado devido à força de gravidade. O aparelho vestibular auditivo também consegue se ajustar a "novas" mudanças de direção na verticalidade corporal, quando consegue propor impulsos de aceleração do corpo nas curvas e, assim, em 
vez de perda do equilíbrio, ocorre, com grande precisão, o controle do corpo em movimento. Em uma postura corporal normal ereta, a dimensão vertical do corpo coincide com a direção da força de gravidade, de modo que a dimensão do "em cima - em baixo" é orientada somente por essa força.

A relação funcional dessa dimensão se expressa como resultado do trato com o mundo e com as coisas: a dimensão do "em baixo", por exemplo, como uma experiência com relação ao peso das coisas e à dimensão do "em cima", relaciona-se com a questão do esforço para levantar algo ou com aquela preocupação de chegar em um lugar mais alto, ou ainda, ao contrário, com o perigo de cair de um lugar muito alto.

\subsubsection{A dimensão corporal esquerda-direita}

Diferentemente da dimensão "em cima - em baixo", falta para a dimensão corporal esquerdadireita pontos de referência externos mais precisos. Como orientação, as dimensões de "esquerda" e de "direita" são conduzidas corporalmente, de modo que, com base na sua simetria longitudinal, o próprio corpo não pode ser tomado para a estruturação do ponto de referência no caso. Em uma estruturação espacial, a dimensão direita-esquerda somente se funda em contexto funcional. Nesse caso, o eixo da simetria espacial funciona como uma espécie de "divisor espacial" muito preciso. O eixo da simetria espacial divide, nesse caso, o espaço de ação em um espaço onde as dimensões esquerda e direita aparecem. Dessa forma, diferenciamos a posição de um objeto da mesma forma como as direções que os movimentos realizados sugerem, enquanto esquerda ou direita são colocados exatamente ao longo dessa linha.

Essa subdivisão se torna uma referência espacial funcional devido a um princípio de economia nas ações executadas, porque os pontos de referência, com os objetos e os espaços, podem ser alcançados com um menor esforço neste caso. Assim, temos, por exemplo, um objeto que está situado à esquerda de alguém, sendo, normalmente, agarrado com a mão esquerda, para que se mantenha a posição do corpo em equilíbrio. Também nesse caso, se formos em direção à direita, ou girarmos para o lado direito, geralmente damos o primeiro passo com o pé direito. Esse princípio, porém, poderá ser violado quando ocorrer um cruzamento do eixo simétrico lateral, por exemplo, na situação em que um objeto pode ser facilmente agarrado com a mão esquerda, mas, devido a uma grande habilidade de um atleta, no caso, é agarrado com a mão direita, mesmo dirigido mais para o espaço à esquerda. Isso, porém, só se torna possível através de rotação do corpo, conseguindo, assim, deslocar propriamente o objeto em questão para o espaço em que a mão mais adequada poderá interceptar o objeto em movimento. 


\subsubsection{A dimensão corporal frente - atrás}

A dimensão frente - atrás é o eixo central do direcionamento de uma locomoção. Para o Ser Humano, existe uma clara dominância pelo espaço da frente, ele é o espaço da ação humana. A razão para isso vem da própria anatomia. Os órgãos dos sentidos do Ser Humano são frontais ou estão orientados para a frente, principalmente, a posição frontal dos olhos, que tem como consequência o fato de que somente o espaço a nossa frente pode, de fato, ser totalmente observado e estar a nossa disposição. O espaço atrás de nós não pode ser observado e, portanto, não fica a nossa disposição. Por esse motivo, não é articulado, sendo confuso e indisponível para ações, se comparado ao espaço da frente. O espaço atrás tem uma extensão muito menor que o espaço da frente, o que significa que a localização no espaço fenomenal não é centralizada, mas periférica.

O espaço atrás é funcionalmente dado como um espaço para recuar. Em razão disso, podemos nos mover mais desajeitadamente do que no espaço da frente. Na prática esportiva, podem surgir tarefas motoras bem especiais, a exemplo de um jogo de futebol, quando é necessária a realização de um movimento para um espaço incontrolável e de pouca ou nenhuma possibilidade observativa direta. Nesse caso, e nos esportes, é preciso achar um modo de estruturar e controlar esse espaço também, o que só pode ser alcançado através de múltiplas e diversificadas experiências de movimento no campo de jogo, em situações em que este espaço, que fica às costas dos jogadores. Só pode ser estruturado e ampliado como um espaço funcional relevante através de experiências concretas e significativas de deslocamentos no campo de jogo.

Por esse motivo, temos a tarefa importante, por exemplo, em aulas de Educação Física Escolar, de desenvolver noções de espaço pelo "se-movimentar" de alunos na aprendizagem de movimentos esportivos adequados para esse desenvolvimento.

\subsection{Estruturação do espaço percebível pelas ações concretas}

Nas ações de um "se-movimentar humano", a percepção espacial é estruturada a partir da intencionalidade dessas ações de movimento. Nos espaços de ações de movimento, abrem-se caminhos importantes, muito significativos para a realização das intenções de movimento e, de forma destacada, ainda sugerem áreas e lugares enquanto espaços disponíveis para a intencionalidade dos movimentos desejados. "O espaço, portanto, aparece para um atleta treinado, não como um meio de atuação neutro, 
mas como um espaço para um agir plástico, permeado por linhas de força que cortam esse campo de ação" (THOLEY, 1984, p.21).

Quando um passe, no caso do futebol, for realizado das linhas de fundo de um campo de futebol, na tentativa de alcançar, com a bola, um companheiro de jogo, e este poder realizar uma jogada que resulta em gol, o espaço de ação, nesse caso, assumirá um significado bem diferente do que se esse mesmo jogador, ao invés de realizar esse passe ao atacante, na linha de frente, passasse a bola apenas a um companheiro mais perto.

O exemplo acima mostra uma segunda forma de estruturação espacial, ou seja, uma configuração de ações intencionais no jogo. A estrutura intencional é concretizada em formas de ações antecipadas, que garantem maior diferenciação de espaço nas ações movimentadas. A perspectiva de ação da defesa, no fundo do espaço de jogo, com relação ao passe anteriormente descrito, concentra-se na percepção de lacunas que servem, então, como possibilidades de ações relevantes, coordenadas e altamente dinâmicas, permitindo ações que resultem em êxito, para o caso dos defensores.

Uma terceira forma de estruturação é aquela que diz respeito à amplitude da área de ação. Os espaços de ação, como nos referimos anteriormente, podem ser estruturados em diferentes densidades e se estenderem em diferentes amplitudes. As áreas de ação são, portanto, limitadas horizontalmente pela amplitude dos projetos intencionais e incluem o que poderia ser descrito, no entendimento de MerleauPonty (1966, p.123), como “a extensão espacial do corpo intencional”. A dimensão da extensão não pode ser menosprezada, por se tratar de um fator de forte influência no controle prático do espaço durante eventos esportivos. Isso pode ser muito bem ilustrado ao compararmos o comportamento de crianças, com relação ao espaço, em um jogo de futebol, com jogadores treinados da mesma modalidade esportiva.

Dessa forma, podemos perceber que as intenções das crianças se dirigem, principalmente, para a posse de bola. Por esse motivo, seu espaço de ação fica bem limitado. É fácil de ser percebido quando vemos esses jogos, em que se formam verdadeiros "grupinhos" ao redor da bola em disputa.

Para jogadores de futebol experientes, todo o campo de jogo é estruturado como um espaço de ação na forma de possíveis espaços para a condução da bola ou mesmo para deslocamentos no campo de jogo. Para eles, também existem outras regiões espaciais, algumas em forma de subáreas específicas, como zonas de defesa e de ataque. Esses são então, os espaços, em geral, onde o jogo se concentra mais, embora existam, também, áreas com baixa densidade de atividade ou na forma de espaços de controle ou de espaços abertos, onde o espaço de ação não é tão intenso ou congestionado. 
“Em um jogo de futebol, no entanto, tudo se torna mais complicado pela presença do time adversário", escreveu Sartre (2010). De fato, a interação da ordem espacial, em jogos esportivos, torna-se extremamente complexa, pois, no caso, duas equipes competem para formação do ordenamento espacial. Quando a equipe adversária impõe seu próprio jogo, isso significa dizer que ela está configurando seu próprio ordenamento espacial e, ao mesmo tempo, impedindo ou desconstruindo o ordenamento espacial da equipe adversária. Ataques rápidos, mudanças também rápidas na condução ou passe da bola, assim como chutes de curta e longa distância, conseguem, na maioria das vezes, impedir que a defesa da equipe adversária organize o seu espaço para impedir jogadas mais perigosas da outra equipe, ou seja, a organização do espaço de jogo fica enormemente dificultada.

Se o professor acredita que isso é o correto, ele se engana. Para aprender a realizar um passe, a partir de um espaço de profundidade do campo de jogo, a repetição desse passe, de forma isolada, deve ser mais difícil do que na prática desse mesmo passe em situação de jogo, porque, na situação isolada, encontram-se orientações espaciais diferentes e uma estrutura intencional espacial também diferente. Em situação de jogo, o aprendiz precisa identificar lacunas e espaços que permitam a realização do passe, ou seja, ele necessita identificar o risco de fazer um passe mal feito. Já em situações de treino repetitivo do fundamento passe, no futebol, de forma isolada, trata-se de somente aperfeiçoar o passe mais correto para o companheiro de jogo.

\section{Orientações para a promoção do desenvolvimento humano}

Crianças, em Países como o Brasil, identificam-se muito com os jogadores de futebol. Alguns jogadores, como Neymar, na atualidade, tornam-se verdadeiros ícones de sua época, também, muitas vezes, entendidos como típicos representantes de esperança social. O ícone torna-se, assim, um símbolo de identificação para orientação no contexto social. Espelhadas no ídolo, fica mais claro para crianças, especialmente, quem elas são e como elas se veem.

Nessas considerações, estamos nos referindo, especialmente, a um conceito de autossimbolização da criança, apresentado por Günther Bittner (1981). De acordo com Bittner (1981, p. 203), a formação de autossímbolos, na criança e no jovem, é um componente necessário para um autoconhecimento e formação de Si.

Evidentemente, o ambiente, na Educação Física Escolar, em especial com o ensino de futebol, pode servir também para reforçar ou criar novos ídolos simbólicos. Às vezes, é necessário questionar qual 
é, para a criança e para o jovem, verdadeiramente, o motivo de sua escolha de um ídolo ou símbolo para a vida. No caso Neymar, por exemplo, a criança brasileira, em geral, optou por ele como representante de seu maior ídolo, por quê? Por ter saído de um mundo obscuro e sem brilho para um espaço público mundialmente conhecido? O que isso pode significar para um educador? O que, pedagogicamente, pode ser tematizado nesse caso? Vale a pena a atenção educacional nessas situações? O que realmente é mais relevante para a criança? Como a criança pode assimilar uma interferência nessa situação? O professor tem como negociar com a criança sobre isso? Do ponto de vista didático, Bittner responde a essas perguntas da seguinte forma: a tarefa de ensino escolar deveria estar sempre a serviço da autoexperiência. Isso significa que, simultaneamente, "uma rejeição ao puro ensino adaptativo para aquilo que é útil e socialmente relevante". Isso não significa, por outro lado, dissolver os conteúdos de ensino em uma forma de dinâmica grupal duvidosa, em que se discute de tudo um pouco e se esquece do conteúdo da aula - muito pelo contrário! Temáticas relacionadas a assuntos mitológicos, religiosos, históricos (e acrescentamos culturais; conforme REINER HILDEBRANDT-STRAMANN) oferecem às crianças conteúdos com capacidade de desenvolver e entender o processo de simbolização, sem ser algo que precisa ser legitimado por algum valor social-adaptativo, “o conteúdo não é nada mais do que material para exercitar a alma" (e mais uma vez acrescentamos aí: "meu corpo"; REINER HILDEBRANDTSTRAMANN); ( HUMBOLD);(BITTNER, 1981, p, 203).

\section{Considerações Finais}

$\mathrm{Na}$ formação profissional em Educação Física, no Brasil, é muito evidente a distinção entre a teoria e prática, de modo que, para sua superação, entendemos que o melhor a fazer é aproximá-las para uma coexistência de reciprocidade e complementaridade.

Conforme procuramos mostrar, a fenomenologia se mostra adequada para uma dupla forma reflexiva: uma fenomenologia para o caso do espaço se concentrar sobre os sujeitos da experiência com o espaço. Isso é particularmente importante para estudantes da Educação Física, porque, em geral, quando entram na Universidade, sua consciência do espaço está sempre relacionada à sua experiência com uma biografia esportiva de espaço, que geralmente é baseada em uma compreensão euclidiana do espaço. A partir do curso Universitário, ele começa, então, a aprender a se distanciar dessas experiências biográficas. 
Também é possível, e muito adequado, utilizar a compreensão fenomenológica em aplicações didáticas relacionadas ao ensino de jogos esportivos. Com isso, tem-se, como consequência didática, acima de tudo, que os jogos ensinados e apreendidos, a partir dessa compreensão, seguem o princípio do “aprender brincando", e não, "aprender pela adaptação às destrezas técnica". Didaticamente falando, podemos dizer, então, que o ensino dos jogos esportivos segue o princípio dos "conceitos abertos do ensino de jogos", e não, de "conceitos fechados para o ensino de jogos", por serem mais conhecidos, os processos de ensino-aprendizagem de jogos, na perspectiva da formação de atletas e em que as atividades são regidas no princípio "do fácil para o difícil” ou do "simples para o complexo". Os conceitos de jogos “abertos à experiência" são baseados em uma didática de ensino aberta à experiência (HILDEBRANDTSTRAMANN, 2009), que inclui conceitos genéticos e orientados para o problema no ensino de jogos (BECKMANN; HILDEBRANDT-STRAMANN; WICHMANN, 2009, p. 31-44) ${ }^{1}$.

\section{Referências}

BECKMANN, H.; HILDEBRANDT-STRAMANN, R.; WICHMANN,K. Aprender diante de problemas. In: HILDEBRANDT-STRAMANN, R. Educação Fisica aberta à experiência. Rio de Janeiro: Imperial Novo Milênio, p. 31-44, 2009.

BITTNER, G. Die Selbst-Symbolisierung des Kindes im pädagogischen Kontext. In: BITTNER, G. (Hrsg.). Selbstwerden des Kindes. Ein neues tiefenpsychologisches Konzept . Fellbach: Bonz Verlag, p. 200-205, 1981.

BOLLNOW, O.F. Mensch und Raum. Stuttgart: Kohlhammer. 10. Auflage, 2004.

BUYTENDIJK, F. J. J. Allgemeine Theorie der menschlichen Haltung und Bewegung. Berlin, Göttingen, Heidelberg: Springer Verlag, 1956.

FRANKE, E.; JANSSON, R.. „Spielräumlichkeit” und „Aktionsraum” - Überlegungen zu

einer Handlungsforschung (im Fußball). In: RIEDER, H.; K. BÖS; K.; H. MECHLING, H.; REISCHLE, K. (Hrsg.). Motorik- und Bewegungsforschung. Schorndorf: Hofmann, p. 182-187, 1983.

HILDEBRANDT-STRAMANN, R. Educação Física aberta à experiência. Rio de Janeiro: Imperial Novo Milênio, 2009.

HILDEBRANDT-STRAMANN, R.; HATJE, M. Educação Física como disciplina escolar: Reflexões sobre a disciplinaridade no ensino escolar. Kinêsis. Revista da UFSM. Na impressão. 2020.

HILDEBRANDT-STRAMANN, R.; HATTJE, M.; PALMA, L. OLIVEIRA, A. Currículo modularizado à formação inicial em Educação Física: Uma proposta em discussão. Ijuí/ RS: Ed. Unijuí, 2020.

KUNZ, E. Transformação didático pedagógica do esporte. Ijuí/ RS: Ed. Unijuí, 2020. 9a. Ed.

KUNZ, E. Educação Física: Ensino e Mudanças. Ijuí/ RS: Ed. Unijuí. 2012. 3a. Ed.

${ }^{1}$ KUNZ (2010) considera esse processo da mediação didática como um processo "da transformação didàtico- pedagógica". 
MERLEAU-PONTY, M. Phänomenologie der Wahrnehmung. Berlin: Walter de Gruyter \& Co, 1966.

SARTRE, J.-P. Die Suche nach dem Absoluten. In: BRÜDERLIN, M.; STOOS, T. (Hrsg.) Alberto Giacometti. Der Ursprung des Raumes. Wolfsburg und Salzburg: Eigenverlag; p: 232-237, 2010.

THOLEY, P. Sensomotorisches Lernen als Organisation des psychischen Gesamtfeldes.

In: HAHN, E. ; H. RIEDER (Hrsg.). Sensomotorisches Lernen und Sportspielforschung. Bps Verlag, Köln, p.. 11-26, 1984.

\section{Como citar este artigo}

KUNZ, E.; HILDEBRANDT-STRAMANN, R.; SURDI, A. Das "profundezas do espaço": considerações sobre o jogo de futebol de um ponto de vista da teoria espacial e corporal. Revista Kinesis, Santa Maria, v.39, p.01-17, 2021.

* O presente trabalho não contou com apoio financeiro de nenhuma natureza para sua realização. 